\title{
IT PLATFORM FOR KNOWLEDGE MANAGEMENT IN PROJECTS DEDICATED TO THE SECURITY AND NATIONAL DEFENCE
}

\author{
Grzegorz PILARSKI \\ National Defence University, Warsaw, Poland, \\ g.pilarski@aon.edu.pl
}

\begin{abstract}
Information is one of the most valuable goods in a contemporary hierarchical organization. The necessary condition for an organization to operate properly is to possess certain tools (applications) corresponding with its functional character and enabling basic operations performed on data in a digital form such as gathering, storing and processing. The Management and Command Faculty of the National Defence University makes use of an IT platform for documents' management called Knowledge-Tree to safeguard the realization of project-related activity entailing the basic statue activity as well as projects in the scope of scientific research and development for the benefit of the defence and national security. The aforementioned software allows for inter alia: the creation of a repository of the knowledge base as well as the initiation of the procedure of documents' circulation. In the article, the author will make an attempt to envisage the possibilities of the above-mentioned software and will present the procedure of information circulation which is realized in the parent organizational unit.
\end{abstract}

\section{Keywords: national defence, ICT, knowledge management, DMS}

\section{Introduction}

For a few years now, National Defence University has opened its gates for civil students of the 1st, 2 nd, and 3rd cycle of higher education, which has contributed to the shift of the NDU's concept of strategy through the focus on development as well as cooperation with the private sector, and the continuation of cooperation with the public sector.

An especially important element of the cooperation is the initiation of relations with the world of business, with a number of research-development projects as the main product, in the opinion of the experts from Ernst\&Young, and the final outcome - the increase of innovation due to the effects of the undertaken activities [1].

At the time of the transformation of public institutions, which have to comply with the requirements put in front of them by the EU Policy heading for the commercialization of the prevailing part of the sector, the institutions should adjust to the new reality as fast as possible. It is a difficult task as in most cases there is not enough information concerning the ways of smooth transition from 'stiff organizational structures' into a flexible structure which gives place for the development of its potential as well as it allows to generate profits becoming this way a fully profitable institution of public character based on efficient knowledge management mechanisms.

Mostly, it refers to academic institutions as well as research-scientific centres which constitute the core source of the development potential of every country. Polish scientific potential should be developed as well as noticed and appreciated by investors as a strategic direction of 
investment.

The Management and Command Faculty (WZiD), owing to the character of its activity in the sphere of defence and national security as well as experience gained in the course of the realization of development projects, has the ambition to be a link between the sphere of science and business, supporting this way the development of public institutions providing help due to the so called "know-how".

One of the arguments supporting this assumption is the fact that since 2007 WZiD is an active leader as well as member of project teams with partners from the public and private sectors. These are some of the examples:

PBZ-MNiSW-DBO-02/I/2007

entitled: "Advanced methods of creating situational awareness in network-centric operations"; No. O R00 005006 entitled: "Integration of command systems"; No. O R00 005506 entitled: "Simulation of combat activities in a heterogenic and dispersed simulation"; A-0676-RT-GC JIP-FP realized for the European Defence Agency entitled: "Smart Information for Mission Success"; No. 51/PMKI/U/14-06.10/2011 "Innovation Wizard - support for an innovative, academic, entrepreneurship". To realize projects within this sphere, the organizational unit has to implement and possess proper mechanisms enabling it to perform project activity and at the same time to effectively manage knowledge.

\section{How to manage knowledge?}

Organizations have always been looking for novel solutions aiming at the increase of the effectiveness of their performance. This tendency is inextricably connected with the necessity of change in terms of the structure, management approach, and functioning of an organization. The transition of an organization into the so called project management or/and process management can serve as an example of this type of change. According to experts in management sciences, projects are becoming a business tool to gain competitive advantage.
According to John Buxton [2], "an organization can gain a lot only by implementing a few project patterns, but in an orderly manner. A proper implementation of $20 \%$ of the best patterns can safely bring $80 \%$ of potential benefits." In this type of organizations, tasks and undertakings are realized through certain projects and/or processes. It is often the case that the scope of tasks and undertakings in the process of project realization is so extensive that it requires some assistance in using different IT tools. In the scope of choosing a proper IT tool supporting the process of project running, one can take different criteria of division i.e. basic potentiality, tracking the course of potentiality, resources management, graphic presentations, access to an application, technical capabilities (tools for a group work, support of planning, financial control, etc.) or user's licence (free-of-charge, paid one).

The criteria connected with the type of user's licence are a measurable factor which to a large extent is used by an organization while choosing a proper IT tool to run their own projects.

During the realization of projects in WZiD, a problem was encountered how to properly manage knowledge in the process of project realization as well as after its completion. Finding an answer to this question was not an easy task. After some research connected with the analysis of needs in the scope of project realization in the field of security and defence, an assessment was made concerning software supporting projects available at that time (year 2007) on the market. It was decided to choose an application called Knowledge-Tree (K-T), which satisfies most needs defined during the analysis.

\section{Possibilities of IT platform}

The basic purpose of the chosen software is a document management system (DMS). Knowledge-Tree is a system of documents' management of an open-source class under the licence of GNU (General Public License). The platform enables the 
creation of a repository of documents created in the process of project realization. The functions of the software support the project team most of all in the scope of documents management. Moreover, the implemented mechanisms of information flow make it possible for the platform to initiate e.g. the procedure of documents' approval by many recipients. The platform, supplemented by additional rules connected with the archive and the circulation of documents, can be a priceless tool used by a project team.

\subsection{K-T functionalities}

The basic functionalities of the software include [3]:

- dashboard;

- repository;

- advanced search;

- workflow;

- documents history;

- version control;

- group work on the documents;

- remote access through a webpage;

- viewing users permissions;

- viewing document permissions;

- starting DMS platform only through server installation.

DMS user, depending on the possessed permissions, has different possibilities of using the functions connected with documents' management in a system. The functions can be divided into two basic groups [3]:

- actions on folders;

- document actions.

Functions connected with folders [3]:

- adding documents;

- adding folders;

- renaming folders;

- permissions on viewing and editing;

- performing on the user's local computer operations of mass import of documents (in the form of a zip file) to the system of documents management;

- viewing the history of operations performed on a given folder;
- configuration of the course of work (if the functions of automatic steering commenced by the administrator);

- assigning tasks to groups and users.

Functions connected with documents [3]:

- viewing detailed document's data;

- downloading a document in order to quickly go through it;

- downloading

(temporary blockage) of a document from the system in order to edit it - check-out;

- sending the document back (reactivation) into the system - check-in;

- annulling the operation of downloading a document from the system;

- editing document's metadata;

- transferring a document into a different localization;

- changing a document's name;

- displaying the history of action (transferring, deleting, downloading a document from the system in order to perform some operation, etc.) performed on a document; to a document;

- displaying the history of changes

- document's archives;

- displaying document's workflow;

- displaying permissions (of a group or of users who are to perform a given task) which are set for a document;

- creating a thread of discussion or adding information to an existing thread;

- sending a document via an e-mail to groups or an individual user within an organization;

- displaying or creating links to another document in a repository for a presently chosen document.

\section{Management of K-T platform}

$\mathrm{K}-\mathrm{T}$ platform is a kind of a base to be completed and the way it will be filled up depends only on the user.

System's administrator is equipped with an additional tab with tools enabling the adjustment of the portal's functioning to the 
needs of a user by having influence on forms which allow for the insertion of a document and the structure of access rights to particular resources included in the portal by giving special permissions to the users and the portal's objects.

Owing to the application of additional procedures which are determined in each organization, it is possible to adjust the possibilities of the platform to individual goals. One of the elements which the user has influence on is the K-T catalogue structure. The portal's structure was designed on the basis of the shared catalogues available for a given group of users. Rights to view portal's resources, the possibility to save and modify them can be given to a group or an individual user. A proper policy of access rights management allows the creation of any structure of the portal. An example of the portal's catalogue structure [5] is illustrated by Figure 1 .

Another setting generated by the user of K-T can be the form of document's metadata. After placing each document in the repository, the system displays detailed information on the placed file in the form of the document's details, including inter alia the following information [3]:

- document filename - the name of the file and its size;

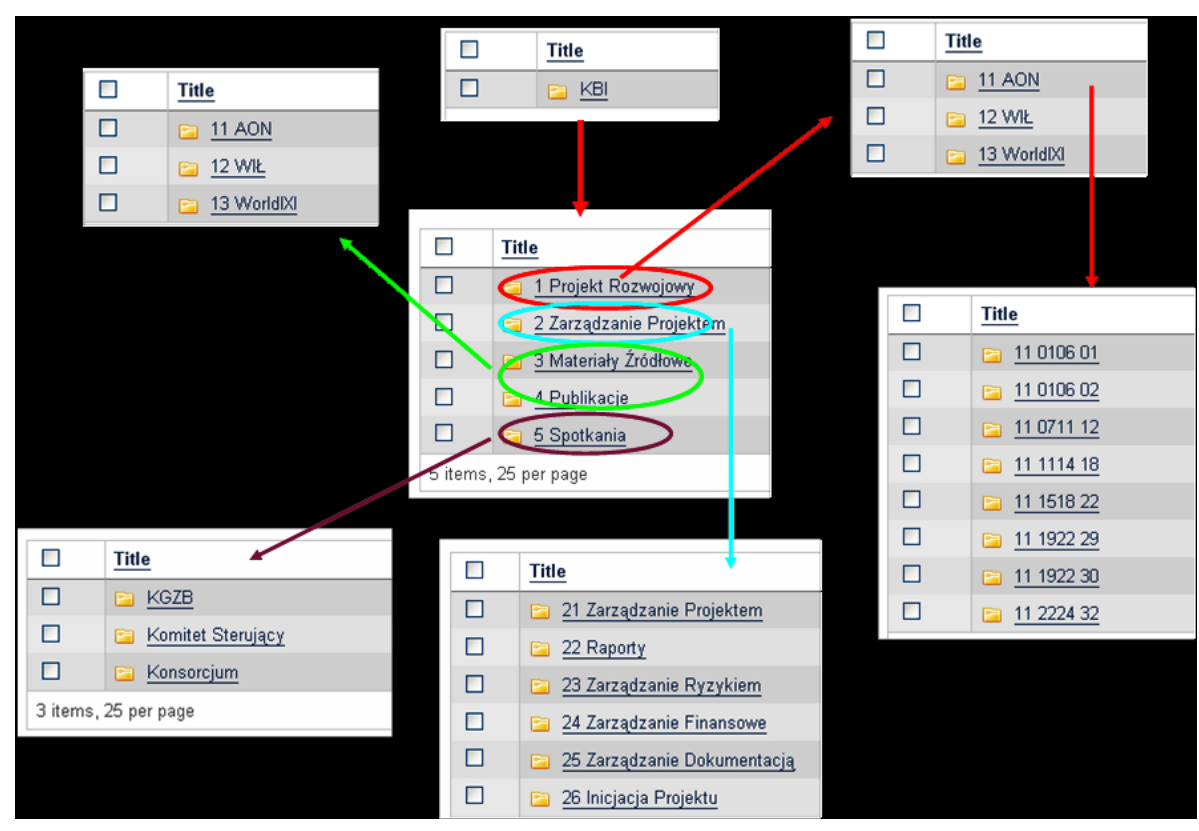

Figure 1: An example of a catalogue structure in Knowledge-Tree platform

- file is a - this is the format the document is saved in;

- document version;

- created by - the author of the document (placed in the system); document;

- owned by - the owner of the

- last update by - who was the last

person to update the document;

- document Type;

- workflow status - the status of the document in its life cycles;
- document ID;

- general information - fields describing general information on the document (it can be changed).

Any document placed in the system can be subject to the so-called workflow process - in a broader sense, the concept determines the manner of information flow between certain objects taking part in its processing. In a narrower sense, it is understood as the definition of the manner of documents' flow between certain users of the 
system in accordance with a given algorithm called document's life cycle.

The concept of workflow is used with reference to a soft ware which is used to support group work. Such a soft ware allows the determination of roles, in the process of documents' processing, played by people participating in a given activity, as well as the intermediate states of documents life. An exemplary document's life cycle [4] which is used during the realization of projects and scientific-research works in WZiD is presented by Figure 2 .

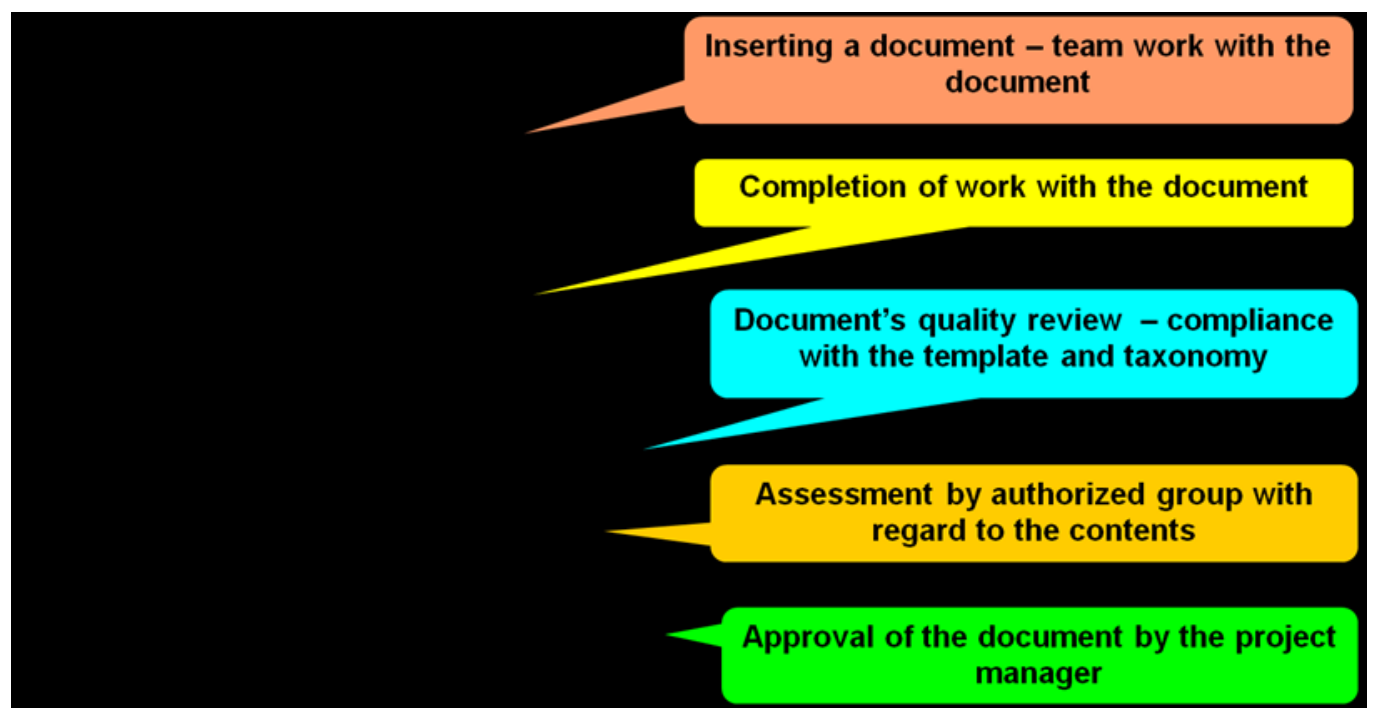

Figure 2: The example of a life cycle of a document implemented onto the Knowledge Tree platform

The cycle of document's life is described by the so called workflow state in which the document exists and transitions between states. Owing to the automatization of the process, the system allows to identify the present state of a document, making it possible to determine its status in the project. Moreover, it determines the conditions which the document has to comply with in order to achieve the next state. The document's life cycle is the way of dealing with the document from the moment it is inserted into the portal till the moment the document is approved by an authorized person, e.g. a project manager.

In the first stage of the cycle ("filed") the document is placed on the K-T platform by the manager of a project task. In accordance with the accepted taxonomy [5], a document is given a certain name and template. At this stage, the research team does research and its results are described in a report. During work ("time start") a document can be created by a group of people since every member of the project team has access to the up-to-date version and has information who at a given moment works with the document. This mechanism is assured by the so called check-out and check-in of the document, which means that a document has a transitive state either busy or free. A given mechanism of making versions allows the management of previous versions of a document and its upto-date version. After completing work with the document, it is approved by the task manager and it is transferred to the stage "ready" which results in a notification of the next team that it has to check the document. At this stage ("time review") a given team is held responsible for the verification of a document in terms of its compliance with the taxonomy and the template. In case of any mistakes, the document is sent back to the previous state with a note that it has to be corrected by the task manager. After a positive assessment, the document is transferred to the stage of substantive assessment "verification". At 
this stage ("time review") the research group analyses the document in terms of its contents. Like before, in case of any mistakes the document returns to the state "filed" with a note to correct it by the task manager and the research team. After a positive review the document is transferred to the stage of assessment by the project manager and after that the document is given the status "authorization". Only at that moment, the document is visible for the rest of the project members; in the previous stages it was visible only for the teams responsible for a particular stage.

Another important element of the portal is the possibility of advanced search for documents. To order the documentation, the user has a possibility to adopt a given taxonomy which makes the process of searching and analyzing the contents of the portal easier. During the realization of projects at the Management and Command
Faculty certain rules were accepted concerning the names of catalogues and of documents which allowed for an easier management of the documentation.

\section{Conclusions}

The tool supporting the process of knowledge management during scientificresearch projects and scientific-research works realized in the Management and Command Faculty is an interesting IT platform which can be used in any organization for this purpose.

It is worth to pay attention to positive assessment given by external assessors after finishing the scientific-research projects, who in the process took into consideration the organization of a project as well as the aspects pertaining to knowledge management at a high level owing to the use of this type of IT platform.

\section{References}

[1] Strategia rozwoju szkolnictwa wyższego w Polsce do 2020 roku, Raport cząstkowy przygotowany przez konsorcjum: Ernst\&Young Business Advisory oraz Instytut Badań nad Gospodarką Rynkową, Luty, 2010.

[2] Computerworld, Raport specjalny, wywiad Piotra Waszczuka z Johnem Buxtonem, marzec 2009.

[3] Knowledge Tree User Manual V3.5.4, 2008 Knowledge Tree Inc.

[4] Pilarski G., Całkowki T., Informatyczne wspomaganie zarządzania procesami w prowadzeniu projektów, Warsaw, AON, p. 94, 2014.

[5] Pilarski G., Instrukcja obstugi portalu konsorcjum KBI, wersja elektroniczna, Warsaw, AON, p. 11, 2010. 